\title{
BMJ Open Effects of family history of diabetes on pancreatic $\beta$-cell function and diabetic ketoacidosis in newly diagnosed patients with type 2 diabetes: a cross- sectional study in China
}

Xiaofen Xiong, Ling Wei, Ying Xiao, Yachun Han, Jinfei Yang, Hao Zhao, Ming Yang, Lin Sun

To cite: Xiong $X$, Wei $L$, Xiao $Y$, et al. Effects of family history of diabetes on pancreatic $\beta$-cell function and diabetic ketoacidosis in newly diagnosed patients with type 2 diabetes: a cross-sectional study in China. BMJ Open 2021;11:e041072. doi:10.1136/ bmjopen-2020-041072

- Prepublication history and additional material for this paper are available online. To view these files, please visit the journal online (http://dx.doi org/10.1136/bmjopen-2020041072).

Received 01 June 2020 Revised 14 December 2020 Accepted 28 December 2020

D) Check for updates

(c) Author(s) (or their employer(s)) 2021. Re-use permitted under CC BY-NC. No commercial re-use. See rights and permissions. Published by BMJ.

Department of Nephrology, The Second Xiangya Hospital, Central South University, Changsha, China

Correspondence to Dr Lin Sun; sunlin@csu.edu.cn

\section{ABSTRACT}

Objective To investigate the association between a parental and/or sibling history of diabetes and clinical characteristics.

Design A cross-sectional study.

Setting The data were collected from the endocrinology department of The Second Xiangya Hospital of Central South University from June 2017 to October 2019.

Participants A total of 894 newly diagnosed patients with type 2 diabetes were recruited. Data on clinical characteristics were collected from patient medical records. Pancreatic $\beta$-cell function and insulin resistance were calculated with the homeostatic model assessment. SPSS V.25.0 was used to perform the analysis.

Results The percentages of patients with parental and sibling histories of diabetes were $14.8 \%$ and $9.8 \%$, respectively. The prevalence of diabetic ketoacidosis (DKA) was $3.9 \%$. Compared with those with no parental history of diabetes, patients with a parental history of diabetes were characterised by early-onset disease $(41.70 \pm 10.88$ vs $51.17 \pm 14.09$ years), poor glycaemic control of fasting blood glucose $(10.84 \pm 5.21$ vs $8.91 \pm 4.38 \mathrm{mmol} / \mathrm{L})$ and a high prevalence of DKA (7.6\% vs $3.3 \%)$. The patients with a sibling history of diabetes had later disease onset $(56.05 \pm 9.86$ vs $49.09 \pm 14.29$ years) and lower BMI $\left(24.49 \pm 3.48\right.$ vs $\left.25.69 \pm 3.86 \mathrm{~kg} / \mathrm{m}^{2}\right)$ than those with no sibling history of diabetes. Univariate regression suggested that both parental history $(\mathrm{p}=0.037)$ and sibling history $(p=0.011)$ of diabetes were associated with $\beta$-cell function; however, multiple regression analysis showed that only a sibling history of diabetes was associated with $\beta$-cell function $(p=0.038)$. Univariate regression revealed a positive correlation between parental history of diabetes $(p=0.023,0 R=2.416,95 \% \mathrm{Cl} 1.132$ to 5.156$)$ and DKA. Unfortunately, this correlation was not statistically significant for either patients with a parental history $(p=0.234,0 R=1.646,95 \% \mathrm{Cl} 0.724$ to 3.743 ) or those with a sibling history $(\mathrm{p}=0.104, \mathrm{OR}=2.319,95 \% \mathrm{Cl} 0.841$ to 6.389) after adjustments for confounders.

Conclusion A sibling history of diabetes was associated with poor $\beta$-cell function, and a parental history of diabetes was associated with poor glycaemic control and a high prevalence of DKA.
Strengths and limitations of this study

- This is the first study to investigate the relationship between a family history of diabetes and diabetic ketoacidosis (DKA) in type 2 diabetes.

- Patients with type 2 diabetes were susceptible to poor $\beta$-cell function and DKA if their family members had a history of diabetes.

- Prospective, multicentre studies and studies including patients with type 1 diabetes should be conducted in the future.

\section{INTRODUCTION}

Globally, there has been an unprecedented increase in diabetes mellitus (DM) such that 366 million people lived with diabetes in 2011, and this number is estimated to rise to 552 million by $2030 .{ }^{1}$ The incidence and prevalence of type 2 diabetes mellitus (T2DM) are much higher in low-income to middleincome countries than in high-income countries, accounting for $80 \%$ of global cases. ${ }^{2}$ For instance, China, as the major epicentre of diabetes in Asia, has a prevalence of $10.9 \%$ and $35.7 \%$ for diabetes and pre-diabetes, respectively. ${ }^{3}$

A family history of diabetes (FHD), which is a common and medically significant finding in medical history records, is a risk factor for various diseases, such as subclinical atherosclerosis, ${ }^{4}$ colorectal cancer ${ }^{5}$ and gestational hypertensive disease ${ }^{6}$ A previous study suggested that patients with an FHD tended to have a higher risk of colorectal cancer (men, HR=1.19, 95\% CI 1.04 to 1.36 ; women, $\mathrm{HR}=1.06,95 \% \mathrm{CI} 0.96$ to 1.17 ) than those without an FHD. ${ }^{5}$ Moreover, an FHD also plays an important role in the prevalence of pre-diabetes, ${ }^{7}$ diabetes risk, ${ }^{8}$ glycaemic control, ${ }^{9}$ and insulin secretion 
and sensitivity. ${ }^{10}$ A multicentre study that included 8106 participants without diabetes revealed that an important risk factor for pre-diabetes $(\mathrm{OR}=1.26,95 \% \mathrm{CI} 1.14$ to 1.40) was an FHD, even after adjustments for potential confounders. ${ }^{7}$ Moreover, data from 9756 Chinese participants noted that their siblings, mothers and fathers had diabetes prevalence rates of $39.3 \%, 38.3 \%$ and $36.4 \%$, respectively. ${ }^{8}$ Additionally, patients with a parental history of diabetes appeared to have an early disease onset and high body mass index (BMI) ${ }^{9}$

Several studies have concentrated on the long-term complications of patients with diabetes who have an FHD,${ }^{11} 12$ such as diabetic retinopathy (DR). ${ }^{11}$ A retrospective study focusing on the parental history of diabetes and DR found that a parental history of diabetes was a risk factor for DR (OR=1.9, 95\% CI 1.09 to 3.5) after adjusting for potential confounding factors. ${ }^{11}$ However, little attention has been given to an FHD and diabetic ketoacidosis (DKA), a life-threatening complication mainly characterised by hyperglycaemic and ketosis with a $1 \%-5 \%$ fatality rate. ${ }^{13}$ It remains unclear whether DKA is associated with an FHD and whether the association degree may differ among different first-degree relatives, such as parents and siblings.

In addition, some studies have found that an FHD also plays an important role in residual $\beta$-cell function, but the results remain controversial. ${ }^{14-16}$ On the one hand, one study demonstrated that patients with an FHD had significantly lower levels of C-peptide than those without an FHD. ${ }^{15}$ On the other hand, another study reported that the impact of an FHD on the C-peptide level was definitely weak. ${ }^{16}$ Moreover, a Japanese study suggested that an FHD was associated with $\beta$-cell function and that the association degree differed based on the type of firstdegree relationship, such as a sibling history of diabetes or a parental history of diabetes. ${ }^{14}$ However, multiple studies have focused on T2DM with a long duration, and no reports have accurately shown the relationship between an FHD and various clinical characteristics, such as residual $\beta$-cell function and glycaemic control, in newly diagnosed Chinese patients with T2DM.

Under such a background, this study aimed to investigate the relationship between a parental or sibling history of diabetes and clinical data, particularly glycaemic control, residual $\beta$-cell function and DKA.

\section{METHODS}

\section{Study population}

The study included 894 patients who were newly diagnosed with type 2 diabetes in the endocrinology department of The Second Xiangya Hospital of Central South University from June 2017 to October 2019. The exclusion criteria were as follows: type 1 diabetes, latent autoimmune diabetes in adults, age under 18 years, known pancreatic disease such as pancreatitis or pancreatic cancer, or missing data pertaining to the FHD.

\section{Data collection and measurements}

Data on the following clinical characteristics of the patients were collected: sex, age, drinking habits, BMI, waist-to-hip ratio (WHR), FHD, complications and use of drugs. Additionally, the following laboratory data were collected: fasting blood glucose (FBG), glycosylated haemoglobin $\left(\mathrm{HbA}_{1 \mathrm{C}}\right)$, albumin $(\mathrm{Alb})$, total cholesterol (TC), low-density lipoprotein cholesterol (LDL-C), highdensity lipoprotein cholesterol (HDL-C), triglyceride (TG) and serum C-peptide levels in fasting samples.

Haemoglobin concentrations and platelet (PLT) counts were measured with an ADVIA 2120 automated haematology analyser (Siemens Healthcare Diagnostics, Germany). Blood chemistry testing, measuring FBG, Alb, TC, TG and serum creatinine, was performed with standard automated enzymatic methods (Hitachi 912 automated analyzer). The measurement of HDL-C and LDL-C was based on lipoprotein electrophoresis and the Friedewald formula, ${ }^{17}$ respectively. In addition, automatic high-performance liquid chromatography (VARIANT-II Haemoglobin Testing System; Bio-Rad Laboratories, Hercules, California, USA) was applied to evaluate $\mathrm{HbA}_{1 \mathrm{C}}$ levels. The chemiluminescence method was applied to evaluate the fasting C-peptide level using the Adiva Centaur Systema kit (Siemens, Munich, Germany).

\section{Definitions}

The diagnosis of DM was based on the criteria of the American Diabetes Association. ${ }^{18}$ An FHD was defined as a first-degree family member (parents, siblings, excluding children) with the presence or absence of diabetes. Calculations of BMI and WHR were based on the following formulas: weight $(\mathrm{kg}) /$ height $\left(\mathrm{m}^{2}\right)$ and waist circumference/hip circumference, respectively. Patients with a drinking history of more than 1 year were defined as drinkers. Drug use referred to regular medications taken for more than 3 months. Hypertension (HTN) was defined as systolic blood pressure (SBP) greater than $130 \mathrm{~mm} \mathrm{Hg}$ and/or diastolic blood pressure (DBP) greater than $80 \mathrm{~mm} \mathrm{Hg}$ with three sequential measurements at different time points. ${ }^{19}$ The definition of DKA was based on the following criteria: a concentration of blood bicarbonate of $<15 \mathrm{mmol} / \mathrm{L}$, or $\mathrm{pH}$ of $<7.25$ (venous) or $<7.30$ (arterial or capillary), or a diagnosis of DKA in the medical records. ${ }^{20}$

\section{Calculation of $\beta$-cell function and insulin sensitivity}

The homeostasis model assessment (HOMA) was used to estimate $\beta$-cell function (homoeostatic model assessment 2-B (HOMA2-B)) and insulin resistance (homoeostatic model assessment 2-insulin resistance (HOMA2-IR)) based on FBG and fasting C-peptide, which were calculated with the HOMA calculator (University of Oxford, Oxford, UK), as described in previous studies. ${ }^{21} 22$

\section{Statistical analysis}

Quantitative variables were recorded as the mean \pm SD, and qualitative variables were described as percentages. A 
t-test or the $\chi^{2}$ test was applied to compare the differences between two groups. A non-parametric Mann-Whitney $\mathrm{U}$ test was used when the $\mathrm{p}$ value of the one-sample Shapiro-Wilk test was less than 0.05 . Partial correlation was performed to identify the association between an FHD and clinical characteristics, such as SBP, DBP, metabolic parameters and complications, when adjusted for confounders of sex, age and BMI. Regression was used to evaluate the relationship among $\beta$-cell function, DKA and an FHD after adjustments for confounders, including sex, age, BMI and $\mathrm{HbA}_{1 \mathrm{C}}$ confounders. Quantitative variables in the logistic regression were defined as positive or negative by a cut-off value as follows: $\mathrm{HbA}_{1 \mathrm{C}}(\%)$ : '0' refers to ' $<10$ ' and ' 1 ' refers to ' $\geq 10$ '; BMI $\left(\mathrm{kg} / \mathrm{m}^{2}\right)$ : ' 0 ' refers to ' $<24$ ' and ' 1 ' refers to ' $\geq 24$ '. The data were analysed by SPSS V.25.0, and a p value of less than 0.05 was regarded as indicative of statistical significance.

\section{RESULTS}

\section{Clinical characteristics of the whole cohort}

A total of 894 newly diagnosed patients with T2DM were enrolled in the study. The mean age of this cohort was $49.78 \pm 14.07$ years, and most of them were men, accounting for $66.8 \%$ of the study participants. The mean BMI and WHR were $25.58 \pm 3.8 \mathrm{~kg} / \mathrm{m}^{2}$ and $0.95 \pm 0.07$, respectively. A total of $14.8 \%$ and $9.8 \%$ of the participants had a parental history and a sibling history of diabetes, respectively. Moreover, $26.8 \%$ of the patients had a drinking habit. The mean FBG was $9.20 \pm 4.56 \mathrm{mmol} / \mathrm{L}$, and the mean $\mathrm{HbA}_{1 \mathrm{C}}$ was $10.13 \% \pm 2.8 \%$. The mean HOMA2-IR and HOMA2-B were $1.44 \pm 1.34$ and $50.89 \% \pm 50.03 \%$, respectively. Regarding complications, the prevalence of DKA was $3.9 \%$, and that of HTN was $39.4 \%$ (table 1 ).

\section{Clinical characteristics based on a parental history of DM}

Patients with T2DM with a parental history were characterised by early-onset disease $(p<0.001)$, worse glycaemic control with higher FBG $(\mathrm{p}<0.001)$ and $\mathrm{HbA}_{1 \mathrm{C}}(\mathrm{p}=0.005)$, higher levels of TG $(\mathrm{p}=0.01)$ and TC $(\mathrm{p}=0.012)$, and worse $\beta$-cell dysfunction $(p<0.001)$ than those with no parental history of DM. Moreover, the prevalence of DKA was higher among participants with a parental history of diabetes $(p=0.028)$ than among those with no parental history of DM. Furthermore, there were no significant differences between groups regarding the distributions of other variables, such as sex, BMI, HOMA2-IR and the use of medications (table 2). Next, the study also investigated the clinical characteristics based on paternal diabetes and maternal diabetes. As with the basic characteristics, there were no significant differences in laboratory data, complications or medications between those with and without paternal and maternal histories of diabetes $(p>0.05)$ (online supplemental table 1).

\section{Clinical characteristics based on a sibling history of DM}

The patients with a sibling history of DM had later disease onset $(\mathrm{p}<0.001)$, a lower proportion of men $(\mathrm{p}<0.001)$,
Table 1 Clinical characteristics of the whole cohort presented as mean \pm SD or percentages

\section{Basic characteristics}

\begin{tabular}{|c|c|}
\hline $\mathrm{N}$ & 894 \\
\hline Age (years) & $49.78 \pm 14.07$ \\
\hline Men (\%) & $597(66.8)$ \\
\hline BMI $\left(k g / m^{2}\right)$ & $25.58 \pm 3.84$ \\
\hline WHR & $0.95 \pm 0.07$ \\
\hline $\mathrm{SBP}(\mathrm{mm} \mathrm{Hg})$ & $134.78 \pm 18.32$ \\
\hline $\mathrm{DBP}(\mathrm{mm} \mathrm{Hg})$ & $83.88 \pm 12.73$ \\
\hline Parent history of diabetes (\%) & $132(14.8)$ \\
\hline Sibling history of diabetes (\%) & $88(9.8)$ \\
\hline Drinking (\%) & $240(26.8)$ \\
\hline \multicolumn{2}{|l|}{ Laboratory data } \\
\hline $\mathrm{Hb}(\mathrm{g} / \mathrm{L})$ & $137.60 \pm 19.84$ \\
\hline $\operatorname{PLT}\left({ }^{*} 10^{9} / \mathrm{L}\right)$ & $219.75 \pm 88.10$ \\
\hline FBG (mmol/L) & $9.20 \pm 4.56$ \\
\hline $\mathrm{HbA}_{1} \mathrm{c}(\%)$ & $10.13 \pm 2.8$ \\
\hline Alb (g/L) & $37.24 \pm 4.90$ \\
\hline $\mathrm{TC}(\mathrm{mmol} / \mathrm{L})$ & $4.63 \pm 1.44$ \\
\hline LDL (mmol/L) & $2.87 \pm 1.02$ \\
\hline $\mathrm{HDL}(\mathrm{mmol} / \mathrm{L})$ & $0.98 \pm 0.30$ \\
\hline $\mathrm{TG}(\mathrm{mmol} / \mathrm{L})$ & $2.70 \pm 3.37$ \\
\hline sCre $(\mu \mathrm{mol} / \mathrm{L})$ & $68.45 \pm 38.07$ \\
\hline HOMA2-IR (\%) & $1.44 \pm 1.34$ \\
\hline HOMA2-B (\%) & $50.89 \pm 50.03$ \\
\hline \multicolumn{2}{|l|}{ Complications } \\
\hline DKA & $35(3.9)$ \\
\hline HTN & $352(39.4)$ \\
\hline \multicolumn{2}{|l|}{ Medications } \\
\hline ACEI (\%) & $126(14.1)$ \\
\hline ARB (\%) & $134(15)$ \\
\hline Lipid-lowering agents (\%) & $564(63.1)$ \\
\hline
\end{tabular}

HOMA2-B and HOMA2-IR were applied to estimate the function of $\beta$-cell and insulin resistance, respectively, which were calculated using fasting plasma glucose and C-peptide.

ACEI, ACE inhibitor; Alb, albumin; ARB, angiotensin receptor blocker; BMI, body mass index; DBP, diastolic blood pressure; DKA, diabetic keto acidosis; DM, diabetes mellitus; FBG, fasting blood glucose; $\mathrm{Hb}$, haemoglobin; $\mathrm{HbA}_{1 \mathrm{C}}$, glycosylated haemoglobin; HDL, high-density lipoprotein; HOMA2-B, homoeostatic model assessment 2-B; HOMA2-IR, homoeostatic model assessment 2-insulin resistance; HTN, hypertension; LDL, low-density lipoprotein; PLT, platelet; SBP, systolic blood pressure; sCre, serum creatinine; TC, total cholesterol; TG, triglyceride; WHR, waist-to-hip ratio.

lower BMI $(\mathrm{p}=0.011)$ and worse $\beta$-cell dysfunction $(\mathrm{p}=0.062)$ than those with no sibling history of DM. No significant differences were found in other parameters (table 3). 
Table 2 Clinical characteristics based on parental history of DM

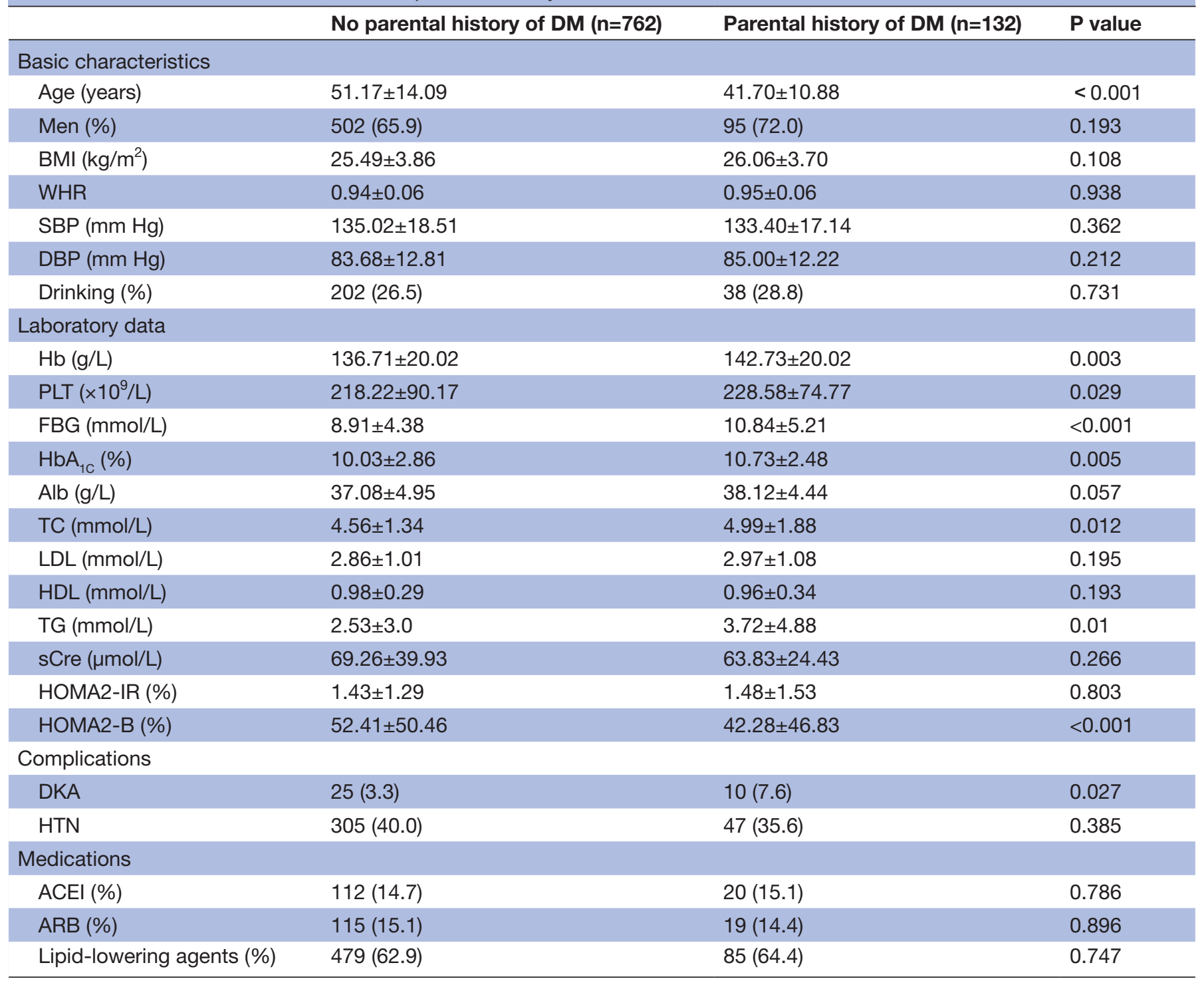

HOMA2-B and HOMA2-IR were applied to estimate the function of $\beta$-cell and insulin resistance, respectively, which were calculated using fasting plasma glucose and C-peptide.

${ }^{*}$ Refers to $\mathrm{p}<0.05$.

ACEI, ACE inhibitor; Alb, albumin; ARB, angiotensin receptor blocker; BMI, body mass index; DBP, diastolic blood pressure; DKA, diabetic ketoacidosis; DM, diabetes mellitus; FBG, fasting blood glucose; $\mathrm{Hb}$, haemoglobin; $\mathrm{HbA}_{1 \mathrm{c}}$, glycosylated haemoglobin; HDL, high-density lipoprotein; HOMA2-B, homoeostatic model assessment 2-B; HOMA2-IR, homoeostatic model assessment 2-insulin resistance; HTN, hypertension; LDL, low-density lipoprotein; PLT, platelet; SBP, systolic blood pressure; sCre, serum creatinine; TC, total cholesterol; TG, triglyceride; WHR, waist-to-hip ratio.

\section{Correlation between an FHD and clinical characteristics}

A parental history of DM showed a positive association with TGs, TC, FBG, $\mathrm{HbA}_{1 \mathrm{C}}$ and DKA, and a negative association with age and HOMA2-B. When the analysis was adjusted for sex, age and BMI, only FBG and $\mathrm{HbA}_{1 \mathrm{C}}$ showed a statistically significant association with a parental history of DM. A positive association was found between a sibling history of DM and age, while a sibling history of DM had a negative association with sex, BMI and HOMA2-B. After adjustments for confounders, FBG and HOMA2-B were correlated with a sibling history of DM (table 4).
Regression analysis between HOMA2-B and DKA and an FHD

The results of the linear regression analysis showed that a parental history $(\mathrm{p}=0.037)$ and a sibling history $(\mathrm{p}=0.011)$ of DM were associated with HOMA2-B. After adjustments for sex, age, BMI and $\mathrm{HbA}_{1 \mathrm{C}}$, a sibling history of DM remained related to HOMA2-B $(\mathrm{p}=0.038)$ (table 5). In addition, a parental history of DM, but not a sibling history of DM, was associated with DKA (OR=1.622, $95 \%$ CI 1.070 to 2.461). Unfortunately, no significant associations for either a parental history or a sibling history remained after adjustment for confounders (table 6). 
Table 3 Clinical characteristics based on sibling history of DM

\begin{tabular}{|c|c|c|c|}
\hline & No sibling history of DM $(n=806)$ & Sibling history of DM $(n=88)$ & $P$ value \\
\hline \multicolumn{4}{|l|}{ Basic characteristics } \\
\hline Age (years) & $49.09 \pm 14.29$ & $56.05 \pm 9.86$ & $<0.001$ \\
\hline BMI $\left(\mathrm{kg} / \mathrm{m}^{2}\right)$ & $25.69 \pm 3.86$ & $24.49 \pm 3.48$ & $0.011^{*}$ \\
\hline WHR & $0.95 \pm 0.07$ & $0.94 \pm 0.06$ & 0.059 \\
\hline DBP (mm Hg) & $83.88 \pm 12.79$ & $83.84 \pm 12.21$ & 0.992 \\
\hline Drinking (\%) & $218(27)$ & $22(25)$ & 0.819 \\
\hline \multicolumn{4}{|l|}{ Laboratory data } \\
\hline $\mathrm{Hb}(\mathrm{g} / \mathrm{L})$ & $137.87 \pm 19.98$ & $135.17 \pm 18.47$ & 0.109 \\
\hline PLT $\left(\times 10^{9} / \mathrm{L}\right)$ & $219.13 \pm 88.22$ & $225.44 \pm 87.34$ & 0.57 \\
\hline Alb (g/L) & $37.27 \pm 4.95$ & $36.88 \pm 4.36$ & 0.247 \\
\hline $\mathrm{TC}(\mathrm{mmol} / \mathrm{L})$ & $4.62 \pm 1.44$ & $4.70 \pm 1.45$ & 0.786 \\
\hline LDL (mmol/L) & $2.86 \pm 1.04$ & $2.99 \pm 0.88$ & 0.196 \\
\hline $\mathrm{HDL}$ (mmol/L) & $0.98 \pm 0.30$ & $0.99 \pm 0.24$ & 0.366 \\
\hline $\mathrm{TG}(\mathrm{mmol} / \mathrm{L})$ & $2.75 \pm 3.42$ & $2.28 \pm 2.88$ & 0.358 \\
\hline sCre ( $\mu \mathrm{mol} / \mathrm{L})$ & $68.99 \pm 39.27$ & $63.56 \pm 23.95$ & 0.12 \\
\hline HOMA2-IR (\%) & $1.45 \pm 1.38$ & $1.31 \pm 0.86$ & 0.639 \\
\hline HOMA2-B (\%) & $52.37 \pm 51.80$ & $37.81 \pm 27.09$ & 0.062 \\
\hline \multicolumn{4}{|l|}{ Complications } \\
\hline
\end{tabular}

HOMA2-B and HOMA2-IR were applied to estimate the function of $\beta$-cell and insulin resistance, respectively, which were calculated using fasting plasma glucose and C-peptide.

${ }^{*}$ Refers to $\mathrm{p}<0.05$.

ACEI, ACE inhibitor; Alb, albumin; ARB, angiotensin receptor blocker; BMI, body mass index; DBP, diastolic blood pressure; DKA, diabetic keto acidosis; DM, diabetes mellitus; FBG, fasting blood glucose; $\mathrm{Hb}$, haemoglobin; $\mathrm{HbA}_{1 \mathrm{C}}$, glycosylated haemoglobin; $\mathrm{HDL}$, high-density lipoprotein; HOMA2-B, homoeostatic model assessment 2-B; HOMA2-IR, homoeostatic model assessment 2-insulin resistance; HTN, hypertension; LDL, low-density lipoprotein; PLT, platelet; SBP, systolic blood pressure; sCre, serum creatinine; TC, total cholesterol; TG, triglyceride; WHR, waist-to-hip ratio.

\section{DISCUSSION}

In this study, we found that patients with a parental history or a sibling history of diabetes had different clinical characteristics. Moreover, a parental history of diabetes was associated with poor glycaemic control and a high prevalence of DKA, and a sibling history of diabetes was associated with poor $\beta$-cell function.

In our study, we found that an FHD was, to the greatest extent, associated with poor $\beta$-cell function, as demonstrated by several studies. ${ }^{10141523}$ A population-based study found that participants with more than three siblings with a history of diabetes plus parents with a history of diabetes presented with the worst glycaemic control and lowest insulin secretion levels among participants in all groups, including those with negative personal, sibling and parental histories of diabetes. ${ }^{10}$ Another study demonstrated similar results, in which a positive history of diabetes was related to insulinopenia in a middle-aged population with diabetes. ${ }^{23}$ In our study, we observed that a sibling history rather than a parental history of diabetes was associated with $\beta$-cell function.

An FHD is reflected by not only genetic factors but also environmental factors. ${ }^{24}$ With the advancement of emerging genetic technologies, numerous candidate 
Table 4 Correlation between family history of diabetes and clinical characteristics

\begin{tabular}{|c|c|c|c|c|c|c|c|c|}
\hline & \multicolumn{4}{|c|}{ Parental history of DM } & \multicolumn{4}{|c|}{ Sibling history of DM } \\
\hline & $\mathbf{r}$ & $\mathbf{P}$ & $a-r$ & a-P & $r$ & $\mathbf{P}$ & $a-r$ & $a-P$ \\
\hline Sex & 0.046 & 0.171 & & & -0.134 & $<0.001$ & & \\
\hline Age & -0.237 & $<0.001$ & & & 0.125 & $<0.001$ & & \\
\hline SBP & -0.031 & 0.357 & -0.031 & 0.357 & -0.037 & 0.266 & -0.034 & 0.319 \\
\hline DBP & 0.032 & 0.334 & 0.002 & 0.958 & -0.015 & 0.653 & -0.002 & 0.951 \\
\hline BMI & 0.06 & 0.077 & & & -0.088 & 0.01 & & \\
\hline TG & 0.075 & 0.028 & 0.026 & 0.45 & -0.018 & 0.6 & 0.011 & 0.753 \\
\hline TC & 0.07 & 0.041 & 0.054 & 0.125 & 0.038 & 0.273 & 0.045 & 0.204 \\
\hline HDL & -0.063 & 0.066 & -0.04 & 0.256 & 0.019 & 0.581 & -0.031 & 0.383 \\
\hline LDL & 0.045 & 0.179 & 0.03 & 0.376 & -0.011 & 0.741 & -0.021 & 0.542 \\
\hline FBG & 0.141 & $<0.001$ & 0.119 & $0.001^{*}$ & 0.054 & 0.109 & 0.075 & 0.028 \\
\hline $\mathrm{HbA}_{1 \mathrm{C}}$ & 0.101 & 0.003 & 0.071 & 0.038 & 0.005 & 0.87 & 0.01 & 0.777 \\
\hline HOMA2-IR (\%) & -0.022 & 0.521 & -0.039 & 0.275 & -0.015 & 0.673 & 0.008 & 0.83 \\
\hline HOMA2-B (\%) & -0.093 & 0.007 & -0.066 & 0.061 & -0.07 & 0.044 & -0.096 & 0.007 \\
\hline DKA & 0.079 & 0.019 & 0.05 & 0.146 & 0.03 & 0.369 & 0.05 & 0.142 \\
\hline
\end{tabular}

a-r and a-p: correlation adjusted for sex, age and BMI.

HOMA2-B and HOMA2-IR were applied to estimate the function of $\beta$-cell and insulin resistance, respectively, which were calculated using fasting plasma glucose and C-peptide.

${ }^{*}$ Refers to $\mathrm{p}<0.05$.

BMI, body mass index; DBP, diastolic blood pressure; DKA, diabetic keto acidosis; DM, diabetes mellitus; FBG, fasting blood glucose; HbA ${ }_{1 C}$, glycosylated haemoglobin; HDL, high-density lipoprotein; HOMA2-B, homoeostatic model assessment 2-B; HOMA2-IR, homoeostatic model assessment 2-insulin resistance; LDL-C, low-density lipoprotein cholesterol; SBP, systolic blood pressure; TC, total cholesterol; TG, triglyceride; WHR, waist-to-hip ratio.

genes related to T2DM have been identified. Many of them, such as RGS16, SYT13 and ENTPD3, are involved in insulin secretion. ${ }^{25}$ It was reported that the Genetic Risk Score (GRS), calculated based on the summation of trait-associated risk alleles of the variants, has a close relationship with clinical parameters, including $\beta$-cell function, glycaemic control and diabetes risk. ${ }^{26-28}$ A study conducted by Walker et al showed that $\beta$-cell sensitivity would be reduced by $39 \%$ if the individuals had more than five risk alleles compared with those who had five or fewer among participants without diabetes. ${ }^{26}$ Moreover, the GRS has been shown to be strongly associated with an FHD. ${ }^{29}{ }^{30}$ One study that calculated a GRS using 33 type 2 diabetes-related variants and examined the relationship between the GRS and a parental history of diabetes found that the mean GRS was increased in accordance with the degree of parental diabetes (zero, one or two parents with a history of diabetes led to a GRS=16.8, 16.9 and 17.1, respectively). ${ }^{29}$ Thus, from the aforementioned reports, we speculated that impaired $\beta$-cell function may be impacted by the GRS.

Surprisingly, in our study, parental history showed no significant association with $\beta$-cell function, while sibling history was related to poor $\beta$-cell function. Several findings have indicated an important role for a sibling history of diabetes. ${ }^{31} 32$ A prospective study with 2960 enrolled participants demonstrated that sibling history played a more important role in diabetes risk than parental history. ${ }^{31}$ However, the possible mechanism remains unclear. The study reported that many environmental or lifestyle factors contributed to the prevalence and incidence of diabetes, such as poor eating habits, a lack of exercise, sleep insufficiency and long duration of depression and stress; among them, many factors may not target

Table 5 Linear regression between HOMA2-band family history of diabetes

\begin{tabular}{llllllll}
\hline & \multicolumn{3}{c}{ Univariate regression } & & \multicolumn{3}{c}{ Multivariate regression } \\
\cline { 3 - 4 } \cline { 6 - 8 } & $\boldsymbol{\beta}$ & $\mathbf{P}$ value & $\mathbf{9 5 \%} \mathbf{C l}$ & & $\boldsymbol{\beta}$ & $\mathbf{P}$ value & $\mathbf{9 5 \%} \mathbf{C l}$ \\
\hline Parental history of DM & -0.072 & $0.037^{\star}$ & -19.628 to- 0.617 & & -0.028 & 0.371 & -12.156 to 4.54 \\
Sibling history of DM & -0.088 & $0.011^{*}$ & -25.761 to-3.357 & & -0.063 & $0.038^{\star}$ & -20.352 to -0.57 \\
\hline
\end{tabular}

Multivariate regression adjusted for sex, age, body mass index, glycosylated haemoglobin and HOMA2-B.

${ }^{*}$ Refers to $\mathrm{p}<0.05$.

DM, diabetes mellitus; HOMA2-B, homoeostatic model assessment 2-B. 
Table 6 Logistic regression between DKA and family history of diabetes

\begin{tabular}{|c|c|c|c|c|c|c|}
\hline & \multicolumn{3}{|c|}{ Univariate regression } & \multicolumn{3}{|c|}{ Multivariate regression } \\
\hline & Wald & $P$ value & OR $(95 \% \mathrm{CI})$ & Wald & $P$ value & OR (95\% Cl) \\
\hline Parental history of DM & 5.205 & $0.023^{*}$ & $2.416(1.132$ to 5.156$)$ & 1.415 & 0.234 & $1.646(0.724$ to 3.743$)$ \\
\hline Sibling history of DM & 0.798 & 0.372 & $1.558(0.589$ to 4.125$)$ & 2.639 & 0.104 & $2.319(0.841$ to 6.389$)$ \\
\hline Constant & 305.636 & $<0.001$ & 0.039 & 72.229 & $<0.001$ & 0.08 \\
\hline
\end{tabular}

Multivariate logistic regression adjusted for sex, age, body mass index and $\mathrm{HbA}_{1 C^{*}}$

${ }^{*}$ Refers to $p<0.05$.

DKA, diabetic ketoacidosis; DM, diabetes mellitus.

$\beta$-cells directly but have distant sites of action. ${ }^{33}$ It is likely that the siblings shared more genetic and environmental factors, such as lifestyle, eating habits and exercise load, which may be attributed to poor $\beta$-cell function. Furthermore, insulin resistance also leads to poor $\beta$-cell function. ${ }^{34}$ However, there was no statistically significant association between a sibling history of diabetes and insulin resistance in our study.

An FHD, an easily obtainable and relatively useful screening tool, has been proven to be a potential risk factor for T2DM. ${ }^{31}$ 35-37 Our study showed that the patients with a parental history of diabetes were younger than those with no parental history of diabetes, which was consistent with several published studies. ${ }^{14}{ }^{38}$ Currently, whether genetic predisposition or lifestyle transformation is responsible for early disease onset in those with a parental history of diabetes is controversial. Alternatively, the improved awareness of diabetic symptoms of those patients could be explained by early disease onset. ${ }^{39}$ In addition, a strong association between $\mathrm{FBG}$ or $\mathrm{HbA}_{1 \mathrm{C}}$ and parental history was observed, even after adjustments for sex, age and BMI, suggesting that the relationship was not influenced by those factors. Gong et $a t^{t 0}$ indicated that individuals with a parental history of diabetes were more familiar with the symptoms of T2DM, which made them underestimate the seriousness of the disease, as they may have observed no immediate consequences of higher blood glucose levels in their family members. Moreover, patients with a parental history of DM had higher TG and TC. However, the results of this partial analysis, adjusted for BMI, age and sex, were not statistically significant. Unhealthy lifestyles, such as drinking and a lack of exercise, are also risk factors for T2DM. ${ }^{41}$ However, our study observed no obvious association between a parental history of diabetes and drinking. A Swedish study incorporating 157549 patients with T2DM revealed that there was a low risk of adoptees developing T2DM if their adopted parents had T2DM, while there was a relatively small increase in the risk if their spouse had T2DM, suggesting a limited impact of environmental factors. ${ }^{36}$ In addition, we found no significant differences in BMI or WHR between patients with no parental history of diabetes and those with a parental history of diabetes, in contrast to the results of several other studies. ${ }^{93741}$
Previous studies focusing on type 1 diabetes have shown that an FHD is associated with DKA. ${ }^{20} 42$ To our knowledge, no studies related to DKA and FHD in T2DM have been reported. In our study, we found that the prevalence of DKA was higher among patients with a parental history than among those without. One study examined the relationship between DKA and gene polymorphisms in gestational diabetes. The results showed that a single-nucleotide polymorphism, rs184187143 in the SLC26A6 gene, was a risk factor for DKA, indicating a possible role for this gene in DKA. ${ }^{43}$ Due to the limited number of observations in large samples and the inclusion of multiple racial backgrounds, the mechanism of genetic inheritance and DKA remains unclear. Moreover, the multivariate regression in our study indicated no association between parental or sibling history and diabetes, which demonstrates a limited impact of genetic inheritance on DKA, and other factors, including poor glycaemic control, may be mainly responsible for it.

In our study, the patients with a sibling history of diabetes were older at the time of diagnosis. The reason for this remains unclear. A possible explanation is their increased awareness of diabetes prevention, which may be due to their observation of the negative impact of the disease on their siblings. Additionally, abnormalities in lipid parameters, such as TC and TG, were not different between those with and those without a sibling history of diabetes, contradicting the results of the Alharithy et a $\hat{l}^{p}$ study. This may be due to adequate use of lipid-lowering agents.

The prevalence of DKA in our study was different from that in a Japanese study $(3.8 \%$ vs $0.48 \%) .{ }^{44}$ Possible reasons are as follows. First, the study population was different. The whole cohort included in our study was newly diagnosed patients with type 2 diabetes, while the Japanese population included both diagnosed and newly diagnosed patients. Second, all of the patients were inpatients in our study, but all 36674 patients recruited in the Japanese study were from outside of the hospital. Additionally, race, clinical differences, and the use of medication may contribute to the differences in the prevalence of DKA. ${ }^{45}$ Compared with that in the Japanese study, the mean age at diagnosis was lower (49.78 vs 51.9 years), and the mean $\mathrm{HbA}_{1 \mathrm{C}}$ was higher (10.13 vs 7.0) in our cohort. 
There are several limitations of this study that should be mentioned. First, detailed FHD information, including whether the parents and siblings had type 1 diabetes or type 2 diabetes, was not collected. Second, this was a cross-sectional study, and more prospective and multicentre studies should be conducted in the future.

In conclusion, patients with a parental history of diabetes had poor glycaemic control and a high prevalence of DKA, while patients with a sibling history of diabetes had poor $\beta$-cell function.

Contributors The data were collected by $X X, L W$ and $Y X$, and the manuscript was written by XX, LW, YX, YH, JY, HZ and MY. LS was responsible for data integrity and accuracy.

Funding This study was assisted by the National Key R\&D Program of China (2018YFC1314002 and 2016YFC1305501) and the National Natural Science Foundation of China (81730018)

Competing interests None declared.

Patient consent for publication Not required.

Ethics approval This study was approved by the human research ethics committees of The Second Xiangya Hospital of Central South University, China. All participants in this study provided informed consent prior to their inclusion in the study.

Provenance and peer review Not commissioned; externally peer reviewed.

Data availability statement Data are available upon reasonable request. Data used in this study can be obtained from the corresponding author.

Supplemental material This content has been supplied by the author(s). It has not been vetted by BMJ Publishing Group Limited (BMJ) and may not have been peer-reviewed. Any opinions or recommendations discussed are solely those of the author(s) and are not endorsed by BMJ. BMJ disclaims all liability and responsibility arising from any reliance placed on the content. Where the content includes any translated material, BMJ does not warrant the accuracy and reliability of the translations (including but not limited to local regulations, clinical guidelines, terminology, drug names and drug dosages), and is not responsible for any error and/or omissions arising from translation and adaptation or otherwise.

Open access This is an open access article distributed in accordance with the Creative Commons Attribution Non Commercial (CC BY-NC 4.0) license, which permits others to distribute, remix, adapt, build upon this work non-commercially, and license their derivative works on different terms, provided the original work is properly cited, appropriate credit is given, any changes made indicated, and the use is non-commercial. See: http://creativecommons.org/licenses/by-nc/4.0/.

ORCID iD

Lin Sun http://orcid.org/0000-0002-4544-0822

\section{REFERENCES}

1 Whiting DR, Guariguata L, Weil C, et al. IDF diabetes atlas: global estimates of the prevalence of diabetes for 2011 and 2030. Diabetes Res Clin Pract 2011;94:311-21.

2 NCD Risk Factor Collaboration (NCD-RisC). Worldwide trends in diabetes since 1980: a pooled analysis of 751 population-based studies with 4.4 million participants. Lancet 2016;387:1513-30.

3 Wang L, Gao P, Zhang M, et al. Prevalence and ethnic pattern of diabetes and prediabetes in China in 2013. JAMA 2017;317:2515-23.

4 Park G-M, Cho Y-R, Lee S-W, et al. Family history of diabetes and the risk of subclinical atherosclerosis. Diabetes Metab 2016;42:170-7.

5 Ma W, Song M, Kværner AS, et al. Sex-specific association between family history of diabetes and risk of colorectal cancer: two prospective cohort studies. Cancer Prev Res 2018;11:canprevres.0159.2018-544.

6 Choi D-J, Yoon C-H, Lee H, et al. The association of family history of premature cardiovascular disease or diabetes mellitus on the occurrence of gestational hypertensive disease and diabetes. PLoS One 2016;11:e0167528.

7 Wagner R, Thorand B, Osterhoff MA, et al. Family history of diabetes is associated with higher risk for prediabetes: a multicentre analysis from the German center for diabetes research. Diabetologia 2013;56:2176-80.

8 Zhang Y, Chen H, Lu H, et al. Prevalence and risk of diabetes based on family history in the Shanghai high-risk diabetic screen (SHiDS) study. Diabet Med 2016;33:1705-11.

9 Alharithy MK, Alobaylan MM, Alsugair ZO, et al. Impact of family history of diabetes on diabetes control and complications. Endocr Pract 2018;24:773-9.

10 Bennet L, Franks PW, Zöller B, et al. Family history of diabetes and its relationship with insulin secretion and insulin sensitivity in Iraqi immigrants and native Swedes: a population-based cohort study. Acta Diabetol 2018;55:233-42.

11 Lapeyre G, Cougnard-Grégoire A, Delyfer M-N, et al. A parental history of diabetes is associated with a high risk of retinopathy in patients with type 2 diabetes. Diabetes Metab 2017;43:557-9.

12 Jali MV, Kambar S, Jali SM, et al. Familial early onset of type2 diabetes mellitus and its complications. N Am J Med Sci 2009;1:377-80.

13 Kitabchi AE, Umpierrez GE, Miles JM, et al. Hyperglycemic crises in adult patients with diabetes. Diabetes Care 2009;32:1335-43.

14 Iwata M, Kamura Y, Honoki $\mathrm{H}$, et al. Family history of diabetes in both parents is strongly associated with impaired residual $\beta$-cell function in Japanese type 2 diabetes patients. J Diabetes Investig 2020;11:564-572.

15 Chung JO, Cho DH, Chung DJ, et al. Plasma C-peptide level is inversely associated with family history of type 2 diabetes in Korean type 2 diabetic patients. Endocr J 2010;57:931-8.

16 Bo S, Cavallo-Perin P, Gentile L, et al. Influence of a familial history of diabetes on the clinical characteristics of patients with type 2 diabetes mellitus. Diabet Med 2000;17:538-42.

17 Palmer MK, Barter PJ, Lundman P, et al. Comparing a novel equation for calculating low-density lipoprotein cholesterol with the Friedewald equation: a VOYAGER analysis. Clin Biochem 2019;64:24-9.

18 American Diabetes Association. 2. classification and diagnosis of diabetes. Diabetes Care 2016;39 Suppl 1:S13-22.

19 Whelton PK, Carey RM, Aronow WS. ACC/AHA/AAPA/ABC/ACPM/ AGS/APhA/ASH/ASPC/NMA/PCNA guideline for the prevention, detection, evaluation, and management of high blood pressure in adults: executive summary: a report of the American College of Cardiology/American heart association Task force on clinical practice guidelines. Hypertension 2017;2018:1269-324.

20 Rewers A, Klingensmith G, Davis C, et al. Presence of diabetic ketoacidosis at diagnosis of diabetes mellitus in youth: the search for diabetes in youth study. Pediatrics 2008;121:e1258-66.

21 Levy JC, Matthews DR, Hermans MP. Correct homeostasis model assessment (HOMA) evaluation uses the computer program. Diabetes Care 1998;21:2191-2.

22 Ahlqvist E, Storm P, Käräjämäki A, et al. Novel subgroups of adult-onset diabetes and their association with outcomes: a datadriven cluster analysis of six variables. Lancet Diabetes Endocrinol 2018:6:361-9.

23 Grill V, Persson G, Carlsson S, et al. Family history of diabetes in middle-aged Swedish men is a gender unrelated factor which associates with insulinopenia in newly diagnosed diabetic subjects. Diabetologia 1999;42:15-23.

24 Cornelis MC, Zaitlen N, Hu FB, et al. Genetic and environmental components of family history in type 2 diabetes. Hum Genet 2015;134:259-67.

25 Lawlor N, Khetan S, Ucar D, et al. Genomics of Islet (Dys)function and Type 2 Diabetes. Trends Genet 2017;33:244-55.

26 Pascoe L, Frayling TM, Weedon MN, et al. Beta cell glucose sensitivity is decreased by $39 \%$ in non-diabetic individuals carrying multiple diabetes-risk alleles compared with those with no risk alleles. Diabetologia 2008;51:1989-92.

$27 \mathrm{Xu} \mathrm{M}, \mathrm{Bi}$ Y, Huang Y, et al. Type 2 diabetes, diabetes genetic score and risk of decreased renal function and albuminuria: a Mendelian randomization study. EBioMedicine 2016;6:162-70.

28 Zheng Y, Ceglarek U, Huang T, et al. Plasma taurine, diabetes genetic predisposition, and changes of insulin sensitivity in response to weight-loss diets. J Clin Endocrinol Metab 2016;101:3820-6.

29 Vassy JL, Shrader P, Jonsson A, et al. Association between parental history of diabetes and type 2 diabetes genetic risk scores in the PPP-Botnia and Framingham offspring studies. Diabetes Res Clin Pract 2011;93:e76-9.

30 't Hart LM, Simonis-Bik AM, Nijpels G, et al. Combined risk allele score of eight type 2 diabetes genes is associated with reduced firstphase glucose-stimulated insulin secretion during hyperglycemic clamps. Diabetes 2010;59:287-92.

31 Chien K-L, Hsu H-C, Su T-C, et al. Sibling and parental history in type 2 diabetes risk among ethnic Chinese: the Chin-Shan community 
cardiovascular cohort study. Eur J Cardiovasc Prev Rehabil 2008:15:657-62.

32 Carlsson S, Midthjell K, Grill V. Influence of family history of diabetes on incidence and prevalence of latent autoimmune diabetes of the adult: results from the Nord-Trøndelag health study. Diabetes Care 2007;30:3040-5.

$33 \mathrm{Kolb} \mathrm{H}$, Martin S. Environmental/lifestyle factors in the pathogenesis and prevention of type 2 diabetes. BMC Med 2017; $15: 131$

34 Rachdaoui N. Insulin: the Friend and the foe in the development of type 2 diabetes mellitus. Int J Mol Sci 2020;21. doi:10.3390/ ijms21051770. [Epub ahead of print: 05 Mar 2020].

35 Valdez R, Yoon PW, Liu T, et al. Family history and prevalence of diabetes in the U.S. population: the 6-year results from the National health and nutrition examination survey (1999-2004). Diabetes Care 2007;30:2517-22.

36 Hemminki K, Li X, Sundquist K, et al. Familial risks for type 2 diabetes in Sweden. Diabetes Care 2010;33:293-7.

37 InterAct Consortium, Scott RA, Langenberg C, et al. The link between family history and risk of type 2 diabetes is not explained by anthropometric, lifestyle or genetic risk factors: the EPIC-InterAct study. Diabetologia 2013;56:60-9.

38 Molyneaux L, Constantino M, Yue D. Strong family history predicts a younger age of onset for subjects diagnosed with type 2 diabetes. Diabetes Obes Metab 2004;6:187-94.
39 Bruce DG, Van Minnen K, Davis WA, et al. Maternal family history of diabetes is associated with a reduced risk of cardiovascular disease in women with type 2 diabetes: the Fremantle diabetes study. Diabetes Care 2010;33:1477-83.

40 Gong L, Kao WHL, Brancati FL, et al. Association between parental history of type 2 diabetes and glycemic control in urban African Americans. Diabetes Care 2008;31:1773-6.

41 Annis AM, Caulder MS, Cook ML, et al. Family history, diabetes, and other demographic and risk factors among participants of the National health and nutrition examination survey 1999-2002. Prev Chronic Dis 2005;2:A19.

42 Hekkala A, llonen J, Knip M, et al. Family history of diabetes and distribution of class II HLA genotypes in children with newly diagnosed type 1 diabetes: effect on diabetic ketoacidosis. Eur $J$ Endocrinol 2011;165:813-7.

43 Zhang F-M, Tian S-X, Geng Y, et al. Novel SIc26a6 gene polymorphism rs 184187143 is associated with diabetic ketoacidosis of gestational diabetes. Eur Rev Med Pharmacol Sci 2019;23:7526-31.

44 Takeuchi M, Kawamura T, Sato I, et al. Population-Based incidence of diabetic ketoacidosis in type 2 diabetes: medical claims data analysis in Japan. Pharmacoepidemiol Drug Saf 2018;27:123-6.

45 Ehrmann D, Kulzer B, Roos T, et al. Risk factors and prevention strategies for diabetic ketoacidosis in people with established type 1 diabetes. Lancet Diabetes Endocrinol 2020;8:436-46. 